\title{
Electronic Gears for Electric Vehicles with Wheel Motor
}

\author{
Yee-Pien Yang \\ Department of Mechanical Engineering \\ National Taiwan University \\ No. 1 Roosevelt Rd. Sec. 4 \\ Taipei, Taiwan Republic of China \\ ypyang@ntu.edu.tw
}

\author{
Tsan-Jen Wang \\ Department of Mechanical Engineering \\ National Taiwan University \\ No. 1 Roosevelt Rd. Sec. 4 \\ Taipei, Taiwan Republic of China \\ r91522809@ntu.edu.tw
}

\begin{abstract}
A novel electronic gearing is proposed in the propulsion system for an electric vehicle driven directly by a wheel motor. This electronic gearing assembles the parallel and serial connections of batteries and motor windings into four gears to accommodate various driving patterns in the permissible range of speed and torque. The objectives of this invention are to extend the speed range of constant power, as well as to improve the driving performance and efficiency of the vehicle. The proposed electronic gearing is tested on a dynamometer to simulate the ECE40 driving pattern, and the driving range is estimated by measuring the state-of-charge of lead-acid batteries, which are normally used as the power source of electric vehicles. The experimental results show that the efficiency increases in terms of the driving range of electric vehicles.
\end{abstract}

\section{INTRODUCTION}

Since the last decade, the air pollution and shortage of petroleum have become critical issues of the modern society. People have grown more concerned with environment preservation and the consumption of existing energy resources. Statistics show that the most severe air pollution originates from imperfect combustion of petroleum of internal combustion engine (ICE) vehicles. Electric vehicles (EVs) are, therefore, driven by environment issues and are becoming increasingly more attractive and promising. Some commercial hybrid cars have been on the street, though the pure electrical vehicle with zero emissions is still in the stage of research and development. Among the research on electric vehicles, the energy source that converts into electricity is one key technology, while energy management is another that provides a more efficient way of consuming limited onboard power.

As to the energy management between various energy sources, Triger et al. [1] proposed that the ICE of a hybrid car must operate at its maximum efficient cruising speed, while the electric propulsion provided extra power when acceleration or significant torque was needed. Then, the size of engine was smaller and it produced less waste gas. Morchin [2] introduced a driving pattern shifting between serial and parallel connections of ICE, motor and batteries to reduce the direct combustion of fuel. Huang and Chang [3] proposed an electrical two-speed propulsion system by switching induction motor windings between a serial connection for starting an electric vehicle and a parallel connection for normal speed operation. Smith et al. [4] and Mellor et al. [5] made use of supercapacitors and flywheels to improve battery performance on the peak power supply to the electric vehicle.

This paper proposes electronic gears in the energy management system of an electric vehicle. This vehicle is equipped with a novel wheel motor directly installed inside of the wheel so that the whole efficiency is improved without any loss from transmissions and differential gears. The purpose of the proposed electronic gears aims to extend the speed range of constant power for the electric vehicle, and to improve the driving range by properly scheduling the gear shifts at their best operating range of efficiency. The experiment on a dynamometer simulates the ECE40 driving pattern, and the state-of-charge (SOC) of the batteries provides an estimation of driving range for the road test.

\section{EV CONFIGURATION AND SPECIFICATIONS}

The electric vehicle is a motorcycle driven directly by a disc-type motor installed inside the rear wheel [6-7]. The wheel motor, as shown in Fig. 1, is designed as a radial-flux, pancake shape, dc brushless motor, with a rotor embedded with 18 magnets and sandwiched by two plates of stator. Each plate of stator has 24 teeth; their windings are assembled into 4 phases. The tire is installed outside on the cover that rotates with the rotor driven by four $12 \mathrm{~V}$ batteries. The maximum torque of the $16 \mathrm{~kg}$ wheel motor is $5.1 \mathrm{~kg}-\mathrm{m}$ at a phase current of $26.7 \mathrm{~A}$ and speed of $100 \mathrm{rpm}$, the maximum power is 2.5 $\mathrm{KW}$, and the torque density is $0.319 \mathrm{~kg}-\mathrm{m} / \mathrm{kg}$.

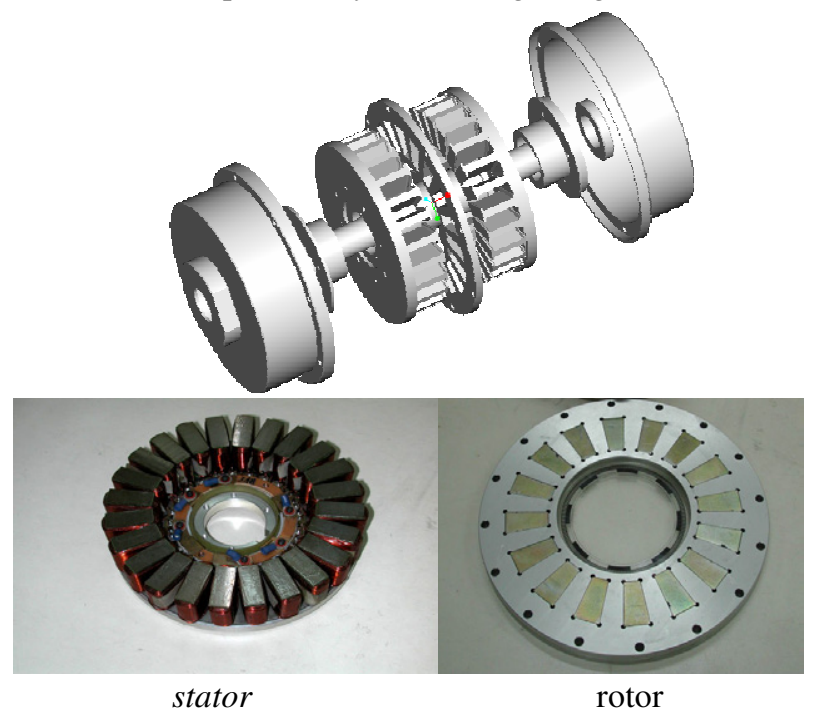

Fig. 1. Wheel motor assembly, stator and rotor.

\section{ELECTRONIC GEARS}

For a power source with a given rating, the ideal profile of 
the traction torque versus speed of a vehicle has a constant torque below the base speed and a constant power above the base speed. For a conventional ICE powered vehicle, a multi-gear transmission is usually designed to achieve a constant power profile. A permanent magnet brushless dc motor has a similar speed- torque characteristic. However its constant power range is usually short due to the limited capability of field weakening, which is only possible by exciting the stator windings with an opposite magnetic field against the permanent magnets on the rotor [8].

The electric propulsion system of electric vehicles is composed of batteries, a wheel motor and its electronic drive. To extend the constant power range of the electric vehicle, the electronic gears of the electric propulsion system have been invented in this research, resembling the multi-gear transmission of conventional ICE vehicles. These electronic gears are formed by various combinations of batteries and stator windings connected in serial and/or parallel configurations. From electrical circuit law, when the wheel motor operates at the stage of low-speed and high-torque, the batteries are connected in parallel and the stator windings are connected in serial so that the partial voltage on windings is low, allowing a higher current to produce a higher torque. When the motor operates at the stage of high-speed and low-torque, the batteries are then connected in serial to achieve high voltage and the stator windings are connected in parallel to dispatch the main current into branches.

The configuration of a 4-battery connection consists of three modes: 4-in-parallel, parallel of 2-in-series, and 4-in-series, as shown in Fig. 2. The internal resistances, capacities and terminal voltages are respectively denoted by $\mathrm{Ri}, \mathrm{Ai}$ and $\mathrm{Vi}$, where $\mathrm{i}=\mathrm{a}, \mathrm{b}, \mathrm{c}, \mathrm{d}$. In the 4-in-parallel mode, the mode capacity becomes $\mathrm{A}=\mathrm{Aa}+\mathrm{Ab}+\mathrm{Ac}+\mathrm{Ad}$ and the mode voltage $\mathrm{Vo}=\mathrm{Va}=\mathrm{Vb}=\mathrm{Vc}=\mathrm{Vd}$. In the parallel of 2-in-series mode, $\mathrm{Vo}=\mathrm{Va}+\mathrm{Vb}=\mathrm{Vc}+\mathrm{Vd}$ and $\mathrm{A}=\mathrm{Aa}+\mathrm{Ac}=\mathrm{Ab}+\mathrm{Ad}$. In the 4-in-parallel mode, $\mathrm{Vo}=\mathrm{Va}+\mathrm{Vb}+\mathrm{Vc}+\mathrm{Vd}$ and $\mathrm{A}=\mathrm{Aa}=\mathrm{Ab}=$ Ac $=$ Ad.

The stator windings are connected in two modes: serial and parallel, as shown in Fig. 3 for a single phase model. On each plate of the stator, three teeth are connected in parallel into one set of windings; two of them are grouped into one phase with opposite electrodes. The serial mode has one phase winding on one stator plate connected in serial with the other phase winding on the other stator plate; while the parallel mode has two phase windings of separate plates in parallel. Then, the batteries and stator windings constitute four electronic gears. Their corresponding phase resistance, phase inductance, terminal voltage and back emf constant are described in Table I, for which the driving conditions are to be determined.

\section{REALIZATION OF ECTRONIC GEARS}

The electronic gears are realized by latching relays and a switching controller. The series-parallel winding connection of a single phase is illustrated in Fig. 4. The parallel connection of the left and right stator windings occurs when relays $\mathrm{R} 1$ and $\mathrm{R} 3$ are closed and $\mathrm{R} 2$ is open, while the closing of R2 and the opening of R1 and R3 bring the windings to the serial connection. A short circuit may occur due to concurrent closing of relays, which brings power from the peak voltage induced in the inductance to damage the MOSFETs. This condition can be avoided by a disabled period between gear shifts, during which all the MOSFETs are set open and the damage power is dissipated. The disabled time of the proposed setting is calculated as $\tau=\mathrm{L} / \mathrm{R}=0.13 \mathrm{mH} / 0.16 \Omega=$ $0.8125 \mathrm{msec}$. For safety reasons, the disabled time prior to the input current being applied for the next gear is assigned at $50 \mathrm{msec}$.

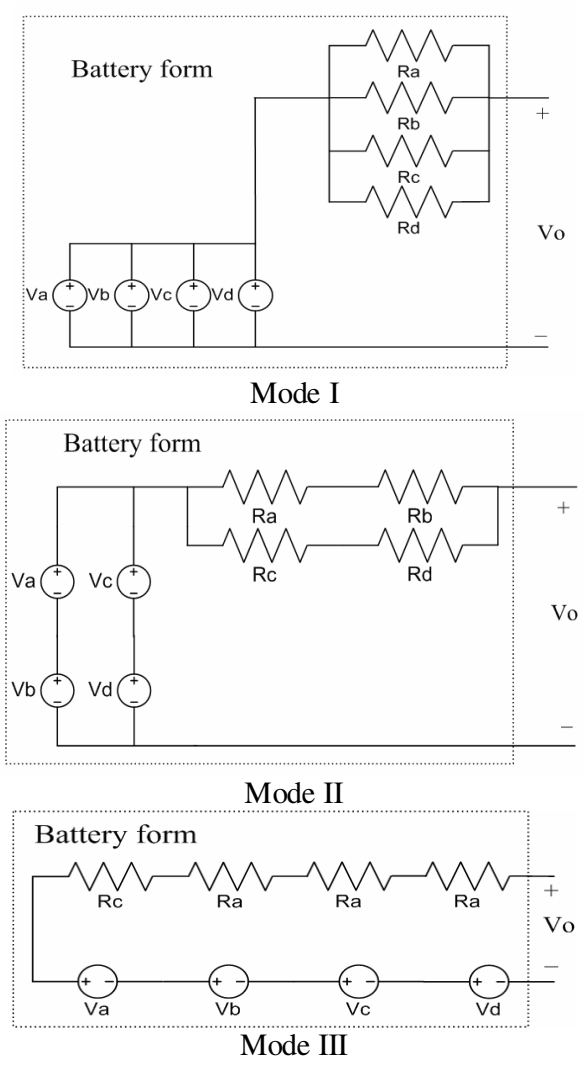

Fig. 2. Battery connection modes
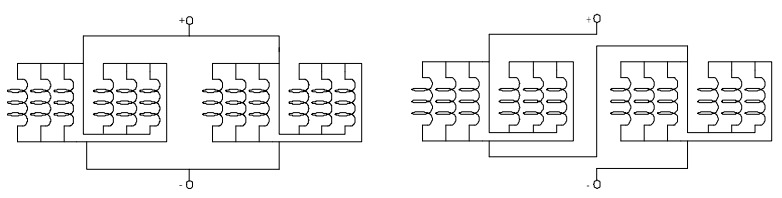

Fig. 3. Parallel (left) and serial (right) phase windings

TABLE I

ELECTRONIC GEAR SHIFTS AND PARAMETERS

\begin{tabular}{lllll} 
Gear & 1 & 2 & 3 & 4 \\
\hline Battery mode & I & II & III & III \\
Capacity $(A h)$ & 112 & 56 & 28 & 28 \\
Winding mode & serial & serial & serial & Parallel \\
Voltage $\mathrm{V}_{\mathrm{o}}(V)$ & 12 & 24 & 48 & 48 \\
Resistance $R(\Omega)$ & 0.16 & 0.16 & 0.16 & 0.04 \\
Inductance $L(\mathrm{mH})$ & 0.18 & 0.18 & 0.18 & 0.045 \\
$K_{b}(V$-sec $/ \mathrm{rad})$ & .711 & .711 & .711 & .355 \\
\hline
\end{tabular}


The realization of series-parallel battery connection is described in Fig. 5, in which each battery voltage is $12 \mathrm{~V}, \mathrm{R} 1$ through $\mathrm{R} 9$ are latching relays, and $\mathrm{V}$ is the output voltage from the battery set. Three output voltages produced by switching 9 relays are scheduled on Table 2; the disabled period is also applied during the switch.

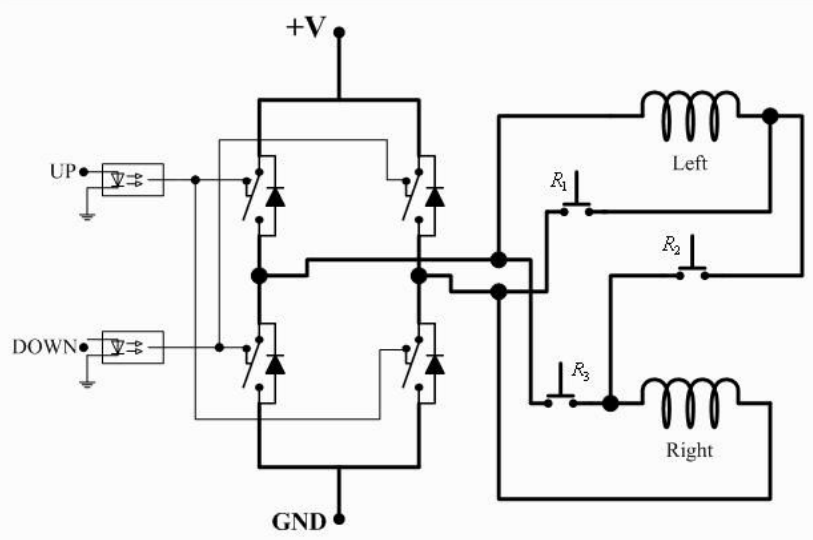

Fig. 4. Realization of series-parallel windings

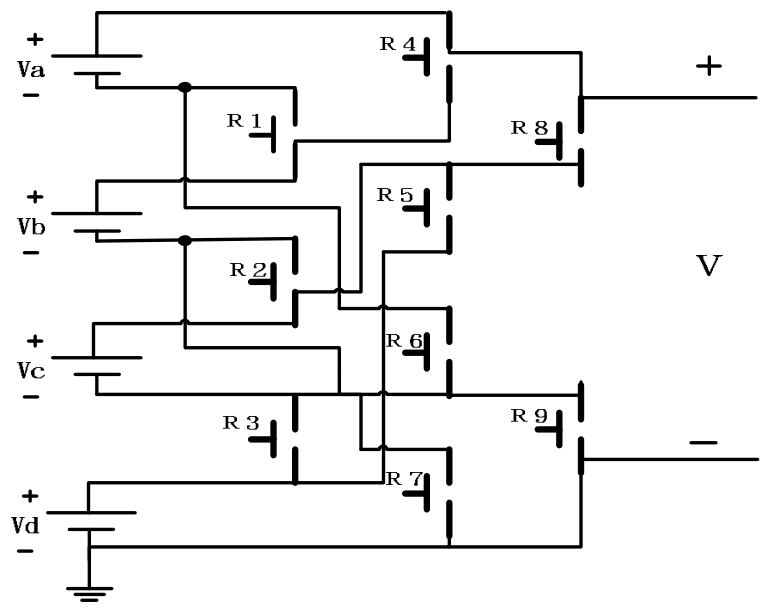

Fig. 5. Realization of series-parallel batteries

TABLE II

SERIES-PARALLEL B ATTERY CONNECTION MODES

\begin{tabular}{lll} 
V & Close & Open \\
\hline 12 & R4 R9 & R1 R3 \\
24 & R1, R3, R8,R9 & R2, R4 R7 \\
48 & R1 R3 & R4 R9 \\
\hline
\end{tabular}

\section{DETERMINATION OF GEAR SHIFT POINTS}

Theoretically, the electrical equation of the motor is expressed as

$$
V_{o}=R i+L \frac{d i}{d t}+E_{b}
$$

where $V_{o}$ is the phase voltage of the wheel motor, $R$ is the phase resistance, $L$ is the phase inductance, and $E_{b}$ is the induced back electro-motive force (back emf). The steady state current is simply

$$
I=\left(V_{o}-K_{b} \omega\right) / R \leq I_{\max },
$$

where $K_{b}$ is the back emf constant so that $E_{b}=K_{b} \omega$. The maximum allowable current $I_{\max }$ per phase is $36 / \sqrt{2} \mathrm{~A}$ in the serial stator winding mode, while $72 / \sqrt{2} \mathrm{~A}$ in the parallel stator winding mode, on the basis of the maximum copper current of $6 \mathrm{~A}$. The maximum motor speed is defined as the critical speed obtained from (2), under which the current waveform does not distort within the maximum allowable back emf limited by applied phase voltage. Below the critical speed, the input current waveform follows the command as the normal back emf, as shown in Fig. 6 for a lower motor speed of $90 \mathrm{rpm}$, thereby producing a maximum output torque. Once it exceeds the critical speed, the back emf waveforms distorts so seriously, as shown in Fig. 7 for motor speed at 500 $\mathrm{rpm}$, that the input current will decay and the corresponding torque cannot be sustained.

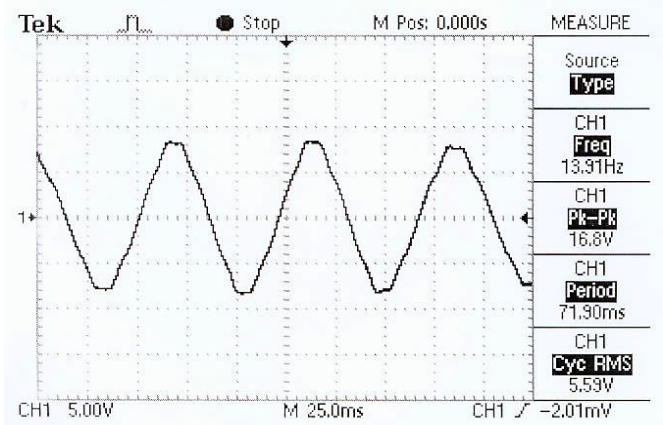

Fig. 6. Back emf waveform at $90 \mathrm{rpm}$

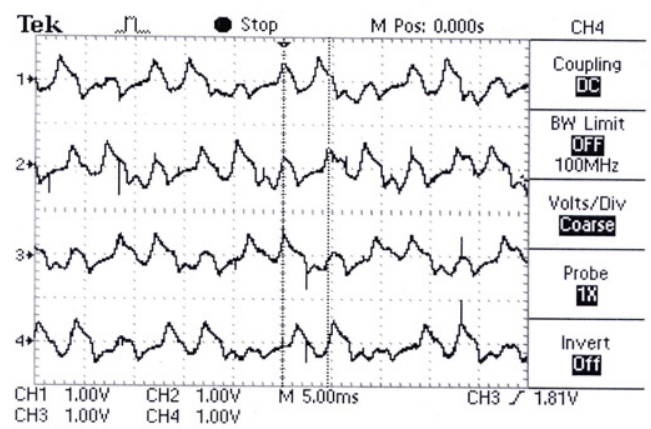

Fig. 7. Back emf waveforms at $500 \mathrm{rpm}$

Therefore, the approximate shift points are better chosen around $50 \mathrm{rpm}$ from the $1^{\text {st }}$ gear to the $2^{\text {nd }}$ gear, $200 \mathrm{rpm}$ from the $2^{\text {nd }}$ to the $3^{\text {rd }}$, and $530 \mathrm{rpm}$ from the $3^{\text {rd }}$ to the $4^{\text {th }}$. However, these do not guarantee an optimal operation in terms of motor efficiency, and have to be adjusted through experiments on the torque and efficiency curves with respect to motor speed.

\section{Torque-Speed and Efficiency-Speed Curves}

The experiments were performed on an eddy current dynamometer, measuring an output torque of up to $7.5 \mathrm{~kg}-\mathrm{m}$, maximum power of $30 \mathrm{hp}$, and a maximum speed of $5000 \mathrm{rpm}$. The electronic gearing scheme was realized on an FPGA, 
Altera FLEX-10KE 200SRC240-1. The experimental set-up also incorporated power supplies, current sensors, and motor drive, as shown in Fig. 8. The torque-speed curves were, therefore, obtained by various current inputs, as shown in Fig. 9 for phase current input of $10 \mathrm{~A}$ (rms), and Fig. 10 of $15 \mathrm{~A}$ (rms). Each plot can be approximately enveloped by an ideal torque-speed curve with constant torque and constant power, with similar base speeds.

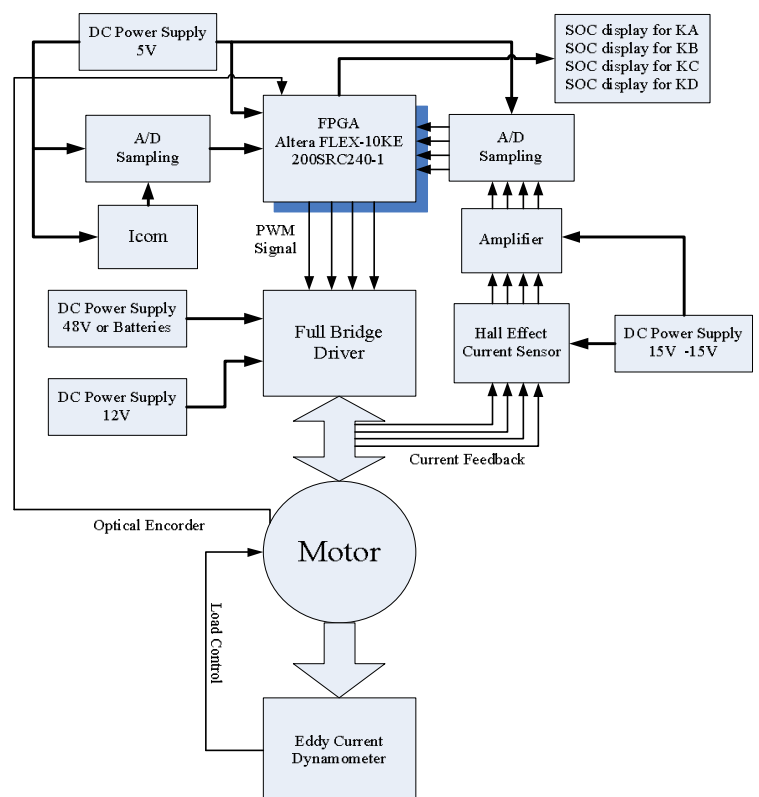

Fig. 8. Experimental set-up

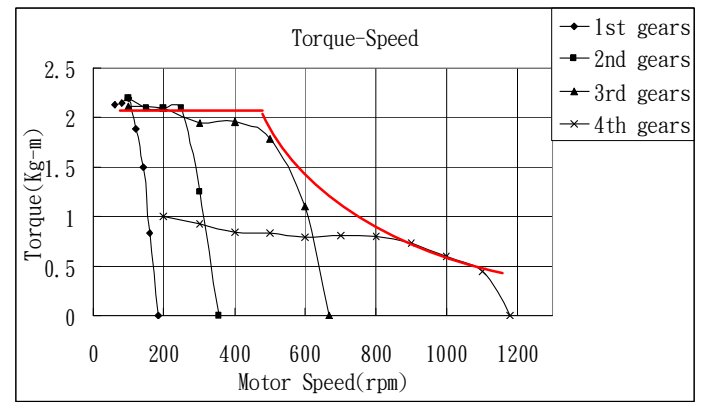

Fig. 9. Torque-speed curve $\left(\mathrm{I}_{\mathrm{rms}}=10 \mathrm{~A}\right)$

Among the torque-speed curves for different phase currents, the shift points are determined by a least change in torque to maintain the smoothness and comfortableness of the vehicle during the transition of gears. The shift points during the acceleration and deceleration must be segregated to avoid vehicle jerks and frequent switching of powered electronic parts. The proposed gear shift is scheduled in Fig. 11.

The corresponding efficiency-speed curves are obtained by taking the average efficiency for various currents in Fig. 12, through which the shift points are determined by keeping the most efficient speed range within a gear mode. A different schedule is then provided in Fig. 13. Both schedules are similar in the range of switching; the gear shift scheduled by efficiency-speed curves is also satisfactory for a smooth gear shift without abrupt changes in torque. Furthermore, the efficiency directly affects the driving range of electric vehicles. The gear shift scheduled by efficiency-speed curves is therefore chosen in the following test.

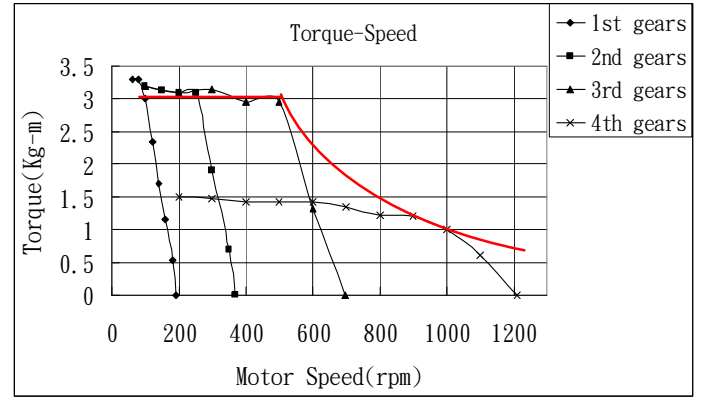

Fig. 10. Torque-speed curve $\left(\mathrm{I}_{\mathrm{rms}}=15 \mathrm{~A}\right)$

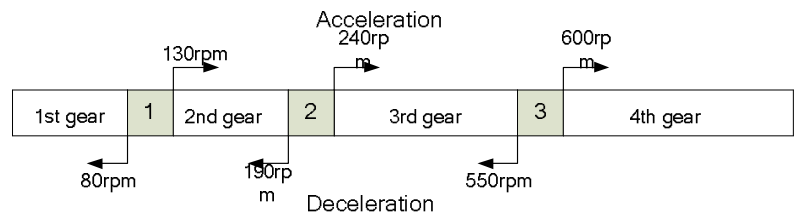

Fig. 11. Gear shift scheduled by torque-speed curves

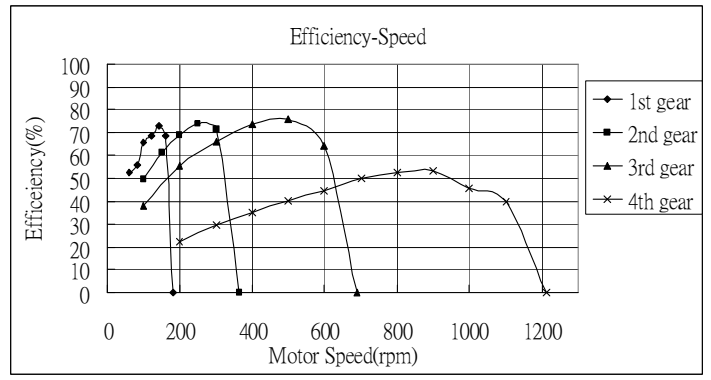

Fig. 12. Efficiency-speed curves

\begin{tabular}{|l|l|l|l|l|l|l|}
\multicolumn{5}{c}{} & \multicolumn{3}{c}{ Acceleration } \\
\hline 1st gear & 1 & 2nd gear & 2 & 3rd gear & 3 & 4th gear \\
\hline
\end{tabular}

Fig. 13. Gear shift scheduled by efficiency-speed curves

\section{ECE40 DRIVING RANGE TEST}

The driving range test is performed according to the ECE40 driving pattern, which is coded on the FPGA that delivers signals to simulate the command given by the driver. The wheel motor is mounted on the dynamometer which provides loading to simulate the inertia of the motorcycle and the friction force on the road. Figure 14 represents the speed curve in experiments, which differs a little from the standard one because the dynamometer does not provide enough real vehicle inertia and road friction.

The driving range should be observed on the road test though, in this moment, it is alternatively measured and estimated in terms of the SOC of the batteries. A set of four $12 \mathrm{~V}$ lead acid batteries are used as the power source, their 
SOC is monitored by measuring their open circuit voltages. Each ECE40 driving cycle corresponds to presumably 1027 meters, the wheel motor stops after five driving cycles, and the open circuit voltages of batteries are measured after the battery set rests for 15 minutes. Figure 15 compares the differences between the average SOC of the battery set between the propulsion system with and without electronic gears for 25 ECE40 cycles. By extrapolation, the driving range with electronic gears extends 5 more cycles over that without electronic gears. The driving range is therefore increased by $20 \%$.

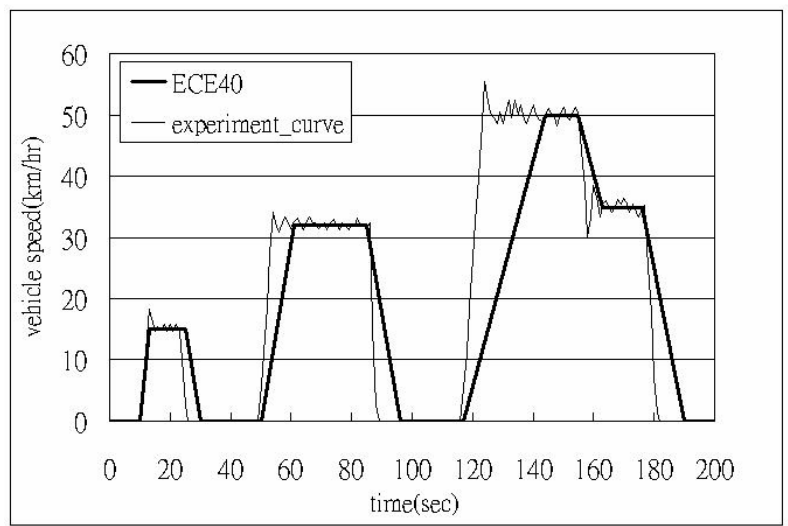

Fig. 14. ECE40 driving pattern (thick: standard, light: experiment)

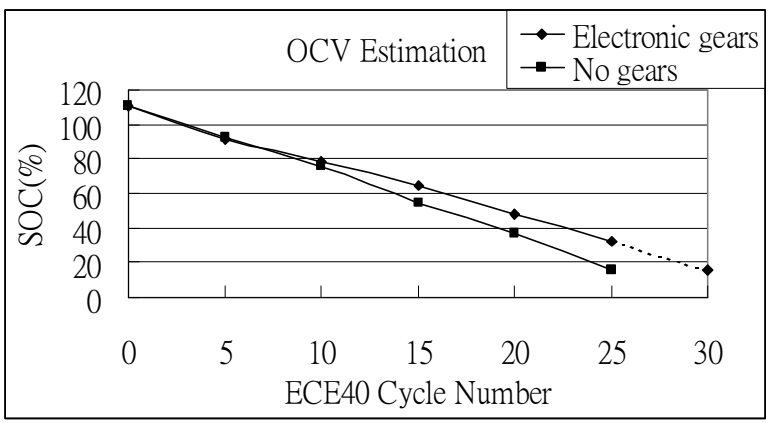

Fig. 15. Battery SOC on ECE40 driving test

\section{SUMMARY AND CONCLUSIONS}

Electronic gears have been successfully invented and implemented on the electric vehicle, extending the operation range of constant power and improving the efficiency of the propulsion system. Each gear has it best range of speed, torque and efficiency that determine a proper shift point between two adjacent gears. At the same time, driving smoothness and comfort have been taken into account. The experiment is performed on a dynamometer to simulate the road test of an ECE40 driving pattern, and the state-of-charge of batteries is measured to estimate the driving range. The test result shows that the driving range is increased by $20 \%$ over the same vehicle without electronic gears. More research may be necessary for the determination of the number of gears, shift points, and the real road test on the driving range.

\section{ACKNOWLEDGMENT}

This work was supported by the National Science Council of Taiwan, R. O. C., under Contract NSC92-2218-E-002-020.

\section{REFERENCES}

[1] L. Triger, J. Paterson, P. Drozdz, "Hybrid Vehicle Engine Size Optimization," SAE. SP-984, Electric Vehicle Power Systems, August 9-12, 1993, pp.33-40.

[2] W.C. Morchin, "Energy Management in Hybrid Electric Vehicles," The AIAA/IEEE/SAE Digital Avionics Systems Conference, Vol. 2, Oct.31-Nov.7, 1998, pp.I41/1-I41/6.

[3] H. Huang and L. Chang, "Electrical Two-Speed Propulsion by Motor Winding Switching and Its Control Strategies for Electric Vehicles," IEEE Transactions on Vehicular Technology, Vol. 48, March 1999, pp.607-618.

[4] T.A. Smith, J.P. Mars and G.A. Turner, "Using Supercapacitors to Improve Battery Performance," IEEE Power Electronics Specialists Conference, Vol. 1, June 23-27, 2002, pp.124-128.

[5] P.H. Mellor, N. Schofield, and D. Howe, "Flywheel and Supercapacitor Peak Power Buffer Technologies," IEE Seminar-Electric, Hybrid and Fuel Cell Vehicles, April 2000, pp.8/1- 8/5.

[6] Y.P. Yang, Y.P. Luh and C.H. Cheung, "Design and Control of Axial-Flux Brushless DC Wheel Motors for Electric Vehicles - Part I : Multi-Objective Optimal Design and Analysis," IEEE Trans. On Magnetics, Vol. 40, No. 4, July 2004, pp.1873-1882.

[7] Y.P. Yang, J.P. Wang, S.W. Wu and Y. P. Luh, "Design and Control of Axial-Flux Brushless DC Wheel Motors for Electric Vehicles - Part II : Optimal Current Waveforms and Performance Test," IEEE Trans. On Magnetics, Vol. 40, No. 4, July 2004, pp.1883-1891.

[8] M. Ehsani, Y. Cao, and S. Gay, "Characterization of Electric Motor Drives for Traction Applications," Industrial Electronics Society, 2003 (IECON '03), The 29th Annual Conference of the IEEE, Vol. 1, 2-6 Nov. 2003 pp.891 - 896.J.S. 